\title{
OS SABERES MOBILIZADOS PELO PROFESSOR DE EDUCAÇ̃̃o FÍSICA PARA CONSTRUÇÃo dA PRÁTICA PEDAGÓGICA
}

\author{
EL CONOCIMIENTO MOVILIZADOS POR EL CATEDRÁTICO DE \\ EDUCACIÓN FÍSICA PARA LA CONSTRUCCIÓN DE PRÁCTICA EDUCATIVA
}
THE KNOWLEDGE MOBILIZED BY THE PROFESSOR OF PHYSICAL EDUCATION TO CONSTRUCT THE PEDAGOGICAL PRACTICE

\author{
Victor Julierme Santos da CONCEIÇÃO ${ }^{1}$ \\ Ramires Mendes MANFIOLETI ${ }^{2}$
}

\begin{abstract}
RESUMO: Identificar os saberes mobilizados pelo professor de Educação Física para dar conta da sua prática pedagógica foi o objetivo desta pesquisa. Fizemos um estudo de caso com observação da escola e dos professores e uma entrevista semiestruturada para coleta de dados. Realizamos a pesquisa em uma escola de Criciúma - SC, com dois professores de Educação Física. Constatamos que os saberes da formação inicial e da formação permanente que influenciam na prática pedagógica dos professores, e como esses saberes são mobilizados pelos docentes para dar conta da sua prática pedagógica. Além disso contatamos os fatores que facilitam ou dificultam a prática pedagógica dos professores e como eles lidam com essas interferências em seu dia-a-dia na escola.
\end{abstract}

PALAVRAS-CHAVE: Saberes docentes. Prática Pedagógica. Formação Permanente. Formação Inicial.

RESUMEN: Identificar los conocimientos movilizados por el profesor de Educación Física para dar cuenta de su práctica era el objetivo de esta investigación. Hicimos un estudio de caso con la observación y profesores de la escuela y una entrevista semiestructurada para la recolección de datos. Llevamos a cabo la investigación en una escuela Criciuma - SC con dos profesores de Educación Física. Se encontró que el conocimiento de la formación inicial y la formación continua que influyen en la práctica educativa de los profesores, y cómo este conocimiento se moviliza por los profesores para dar cuenta de su práctica. También se estableció contacto con los factores que facilitan o dificultan la práctica pedagógica de los profesores y la forma en que se ocupan de tales interferencias en su día - a día en la escuela.

PALAVRAS CLAVE: Maestros conocimiento. La práctica docente. La formación permanente. Formación inicial.

ABSTRACT: Identify the knowledge mobilized by the physical education teacher to give an account of their practice was the objective of this research. We did a case study with observation of the school and teachers and a semistructured interview for data collection. Done research in a school Criciuma - SC with two Physical Education teachers. We found that the knowledge of

${ }^{1}$ Professor Doutor. Universidade Federal de Santa Catarina - UFSC, Colégio de Aplicação e Programa de pós-graduação em Educação - Departamento de Ciências da Educação. Email: victorjulierme@yahoo.com.br

${ }^{2}$ Universidade do Extremo Sul Catarinense. Email: ramiresmanfioletti@hotmail.com 
initial training and continuing education that influence pedagogical practices of teachers, and how these knowledges are mobilized by teachers to account for their practice. Also contacted the factors that facilitate or hinder the pedagogical practice of teachers and how they deal with such interference in their day - to-day at school.

KEYWORDS: Knowledge teachers. Pedagogical Practice. Permanent training. Initial training.

\section{Introdução}

Para Freire (2011), os saberes docentes são algo tão importante que se tornam indispensáveis para os educadores críticos ou progressistas, e ainda alguns deles são igualmente necessários para educadores tradicionais. Esses saberes são oriundos da própria prática pedagógica do educador, seja essa prática tradicional ou progressista.

Este pensamento também é apresentado por Tardif (2002), quando observa que os saberes dos educadores não podem ser separados das outras dimensões do ensino, tão pouco dos estudos que os educadores realizam no seu trabalho diariamente. Seria muito grave falar de saberes como algo isolado da vida cotidiana do educador, mas sim como algo que está mergulhado em seu cotidiano.

Ao educador cabe identificar quais saberes são originados na sua prática pedagógica, e sobre esse saber fazer uma reflexão crítica para que não ocorra divergência entre a prática e a teoria. "A reflexão crítica sobre a prática se torna uma exigência da relação Teoria/Prática sem a qual a teoria pode ir virando blá-blá-blá e a prática, ativismo" (FREIRE, 2011, p.24).

Segundo Freire (2013) "homens são seres da práxis” (p.167). Pois o homem na sua essência busca o quexfazer, sendo seu fazer uma ação e reflexão, objetivando a sua prática, buscando nela um sentido, um porque do fazer, uma teoria que embase o seu fazer, diferentemente dos animais que fazem por puro fazer. "[...] por isso mesmo que estamos defendendo a práxis, a teoria do fazer[...]” (p.172).

Rossato (2009, p. 325) explica que a,

Práxis pode ser compreendida como a estreita relação que se estabelece entre um modo de interpretar a realidade e a vida e a consequente prática que decorre desta compreensão levando a uma ação transformadora. E a partir dessa interpretação do mundo o homem consiga unir elementos que vá fazer com que ele aja com o objetivo de transformar a sua realidade. 
Para falar de autonomia buscamos em Machado (2009), que esclarece que autonomia é o processo de libertação do ser humano das cadeias neoliberais, e faz com que esse sujeito reconheça a história como um tempo de possibilidades. Esse processo que o sujeito passa é um ato que vai sendo construído por ele historicamente, e é fortificada pelas inúmeras escolhas que esse indivíduo vai fazer na sua vida, escolhas essas que vai dar ao indivíduo confiança na sua história e tornando ele dono da sua autonomia.

Este texto é resultado de uma pesquisa, realizada no segundo semestre de 2014, que procurou identificar os saberes mobilizados pelo professor de Educação Física para dar conta da sua prática pedagógica. Tendo como objetivos específicos: descrever os saberes mobilizados na formação inicial dos professores de Ed. Física e as escolhas e caminhos percorridos na prática pedagógica dos professores; compreender como os saberes mobilizados pelos professores de Educação física o ajudam na construção da sua prática pedagógica; identificar os fatores que interferem na prática pedagógica do professor de Educação Física.

\section{Saberes mobilizados na prática pedagógica}

Os saberes docentes, segundo Freire (2011), devem ser compreendidos de forma clara e lúcida pelo professor, e na grande maioria das vezes são elaborados na sua própria prática pedagógica. $\mathrm{O}$ sujeito, desde sua formação, tende a estar ciente que é produtor do saber, e que se convença que ensinar não é transmitir conhecimento, mas sim criar oportunidade para a construção e produção do mesmo.

Tardif (2002) acrescenta ainda que o saber não é algo vago perdido no espaço, ele está relacionado diretamente com o educador, com sua experiência de vida e sua historia profisssional, da relação construída em sala de aula com seus alunos e também com todos os outros integrantes da instituição de ensino. Por isso, quando falamos em saberes devemos sempre ter uma relação direta com o educador, pois são elementos resultantes do seu trabalho docente.

Os saberes docentes são classificados por Tardif (2002) em quatro tipos: saberes da formação profissional, saberes disciplinares, saberes curriculares, saberes experienciais.

O saber da formação profissional é o conjunto de saberes transmitido pela instituição formadora dos educadores, sejam elas escolas normais ou então faculdades de 
ciência da educação. Sendo assim, o professor e o ensino tornam-se objeto de saber das ciências humanas e a ciência da educação. $\mathrm{O}$ vínculo entre a ciência e a prática docente se firma através da formação inicial ou contínua do docente.

Os saberes disciplinares estão mais ligados à formação inicial ou permanente, são saberes oferecidos pelos professores nas disciplinas na faculdade, esses saberes se espalham por diversos campo do conhecimento, esses saberes são resultado da tradição cultural e dos grupos sociais produtores desses saberes, eles se apresentam para nós em forma de disciplina como história, matemática, literatura, esses são exemplos citados por Tardif (2002) para explicar os saberes disciplinares.

Para Tardif (2002) o professor se apropria dos saberes curriculares no decorrer do processo formador, ele se encontra nos objetivos, nos discursos, na metodologia utilizada e aprimorada por ele e os métodos que a instituição de ensino tende a usar para alcançar seus objetivos frente a realidade social em que se encontra. Esses saberes são aprendidos pelo professor de maneira que consiga aplicar no seu cotidiano.

E, por último, os saberes experienciais que Tardif (2002) nos apresenta como aqueles saberes que os próprios professores na função do seu exercício e na sua prática, desenvolvem saberes específicos de cada um, saberes do seu cotidiano e também pela vivência no meio em que ele se encontra.

A prática pedagógica, por sua vez, é abordada por Freire (2011) e interpretada como um processo onde quem ensina se torna parte desse ato, e nesse processo o sujeito que ensina também aprende e da mesma forma quem aprende também ensina, de maneira diferente entre si, mas é um processo de constante aprendizado e ensino. Essa prática pedagógica mobiliza no professor diversos saberes, esses saberes dão condições de construir a sua prática pedagógica de maneira mais eficaz.

Para Libâneo (1994), a prática pedagógica é um ato de extrema necessidade em todas as sociedades, sendo de muita importância para o bom funcionamento e existência dela. Mas não somente isso, ela esclarece os sujeitos dessa sociedade que por fim tende a leva-los ao bom convívio em sociedade e atuarem sobre ela, e transformá-los em necessidade econômicas, sociais e políticas de coletividade. O meio social exerce influência sobre o indivíduo que é tocado por essa prática, e esse indivíduo ao assimilar e fazer relações consegue fazer uma relação ativa e transformadora no seu meio social. Que por sua vez se manifesta por exemplos, valores, crenças e manifestos em geral.

Para Libâneo (1994), em um olhar mais amplo a educação vai dizer o que ocorre e o porquê ocorrem os fatores na sociedade em que os indivíduos estão e são atuantes 
pelo simples fato de estarem ali e ocorrem em diversos lugares, dependendo das condições financeiras, políticas e legais dessa sociedade. E em um sentido mais estrito a educação ocorre em instituições que tem como objetivo instruir os indivíduos ao ensino de uma forma consciente.

\section{Metodologia}

Este estudo é caracterizado como um estudo de caso descritivo; segundo Molina (1999), este tipo de investigação é, sobretudo, uma eleição de um objeto a ser estudado, e não simplesmente uma eleição metodológica. Nessa linha de raciocínio a autora nos afirma que estudo de caso se enquadra perfeitamente em uma pesquisa qualitativa.

Segundo Ludke (1986), a pesquisa qualitativa se caracteriza pela presença do pesquisador em ambiente natural, ou seja, quando o pesquisador observa os fatos na íntegra, no nosso caso quando fomos a escola observar as aulas de educação física e também a escola. A pesquisa também trás em seu meio a descrição de fatos observados, transcrição de entrevistas a fim de coletar o maior numero de informações sobre o fato estudado, o intuito do pesquisar é sempre capturar a percepção dos participantes sobre os fatos ocorridos.

\footnotetext{
A pesquisa qualitativa ou naturalística, segundo Bogdan e Biklen (1982), envolve a obtenção de dados descritivos, obtidos no contato direto do pesquisador com a situação estudada, enfatiza mais o processo do que o produto e se preocupa em retratar a perspectiva dos participantes. (LUDKE, 1986, p.13)
}

Como instrumentos para coleta de dados foram escolhidos, a fim de alcançar os objetivos desse texto, em um primeiro momento a observação das aulas e da escola, essa observação foi intencionada como observador participante (NEGRINE, 1999). Todos os fatos observados foram registrados em um diário de campo para serem transcritos e analisados. Todas as observações, totalizando 5 dias, foram relatadas em um diário de campo, apresentado por Negrine (1999) como umas das estratégias de registro de informações para os investigadores que tem como objetivo coletar informações das suas observações. Também utilizamos uma entrevista semiestruturada; Negrine (1999) observa que essa entrevista é excelente para quando estamos pensando em obter informações concretas, previamente definidas pelo pesquisador. Negrine (1999) alerta que o entrevistador deve ter cautela para não influenciar nos resultados da pesquisa, não 
opinar nas respostas, por exemplo. Fizemos as entrevistas com os professores em dois dias distintos: com a professora Sendy no dia 16 de outubro de 2014, e com o professor Bob no dia 22 de outubro de 2014. Os professores tiveram seus nomes verdadeiros substituídos por nomes fictícios para preservar suas identidades e os aspectos éticos da pesquisa, o mesmo aconteceu com a escola.

Em outro momento elencamos unidades de significado do material empírico e construímos as categorias analíticas, a qual comparamos e fundamentamos com o nosso material teórico, dando ao material coletado um significado a partir do processo de triangulação das informações (MOLINA NETO, 1999).

Observamos abaixo o quadro que apresenta os professores da nossa escola.

A escola tem como espaço para a prática da Educação Física um ginásio com sala de materiais, banheiros e arquibancada. A escola também conta com um espaço externo revestido com lajotas, onde se encontra uma rede de vôlei, um laboratório de informática e também um mini auditório. Esses fatores favorecem os professores na hora da elaboração das suas aulas, mas que são pouco utilizados pelos professores de Educação Física.

Quadro 01- Dados de identificação dos sujeitos da pesquisa.

\begin{tabular}{|c|c|c|}
\hline Professores & $\underline{\text { Sendy }}$ & $\underline{\text { Bob }}$ \\
\hline Estado Civil & Casada & Casado \\
\hline Idade & 26 anos & 38 anos \\
\hline Filhos & Não & Possui uma menina de três anos. \\
\hline Formação Inicial & $\begin{array}{c}\text { Educação Física - Licenciatura } \\
\text { (2010) }\end{array}$ & $\begin{array}{c}\text { Educação Física - Licenciatura } \\
\text { Plena (2003) }\end{array}$ \\
\hline Especialização & Fisiologia do exercício & Treinamento esportivo \\
\hline $\begin{array}{c}\text { Tempo de docência / } \\
\text { tempo de docência na } \\
\text { escola }\end{array}$ & 4 anos/3 meses & 10 anos/8 anos \\
\hline $\begin{array}{c}\text { Carga horária } \\
\text { Outros locais que } \\
\text { executa o seu trabalho }\end{array}$ & $\begin{array}{c}20 \text { horas efetiva no estado (noturna) } \\
40 \text { horas ACT no estado (diurno) }\end{array}$ & $\begin{array}{c}\text { 20 horas efetivo no estado (noturno) } \\
\text { Fenos trabalha com treinamento de } \\
\text { natação. }\end{array}$ \\
\hline
\end{tabular}

Fonte: autores

Para a análise dos dados nos apoiamos em Molina Neto (1999), ao destacar que é importante fazer uma leitura atenta das transcrições das entrevistas e do diário de campo, essa leitura nos remeteu a elencar unidades de significado, unidades essas que são significativas tanto para os professores quanto para o pesquisador, e por isso passam a ter sentido para responder o problema de pesquisa. Essas unidades foram agrupadas e se transformaram em categorias analíticas. 


\section{Formação inicial e formação permanente: uma junção de saberes na prática pedagógica}

Nessa categoria vamos apresentar os caminhos percorridos pelos professores na sua formação inicial, as contribuições da formação permanente e também os saberes que são mobilizados por eles e como esses saberes o ajudam na construção da sua prática pedagógica.

Freire (2011), ao tratar de formação, busca fazer dela uma reflexão, que o docente possa pensar sobre a sua prática e assim avançar constantemente, "aprender para nós é construir, reconstruir, constatar para mudar, o que não se faz sem abertura ao risco e à aventura de espírito.”. (p.77)

$\mathrm{Na}$ formação inicial os professores começaram na área do bacharel, Sendy logo passou para a licenciatura tendo em vista a melhor oportunidade de inserção no campo de atuação, já Bob passou a graduação pensando em trabalhar em academias ou clubes de natação e só se deu conta da escola quando fez o concurso público e passou.

Como podemos observar, nas falas abaixo, os dois professores entraram no curso pelo gosto que tinham pelo esporte, Sendy pelo voleibol e Bob pela natação, já que trabalhava em um clube de natação antes de entrar na faculdade.

Eu sempre quis ser professora de Educação Física porque eu gostava muito de esporte, principalmente o vôlei. (Professora Sendy).

A ideia de fazer o curso de Educação Física foi no meu trabalho no clube no qual trabalho hoje, entrei lá em 1995 auxiliando os professores de natação, eu cuidava desse trabalho lá isso me sortiu um interesse pra fazer, porque eu trocava uma ideia com os professores enfim. [...] e o empurrãozinho foi no clube mesmo, comecei a gostar de natação e comecei a fazer o curso só por causa da natação. (Professor Bob.)

Figueiredo (2008) observa que alunos que atuam na área de Educação Física como auxiliares de profissionais formados e não tem o curso superior, de certa forma se sentem pressionados a fazer a graduação, o que de fato ocorreu com o professor Bob; essas experiências vividas pelo professor como auxiliar são movidas para dentro do curso, fazendo com que o professor crie filtros para selecionar os saberes que julga ser necessários para a sua formação, tendo em vista a sua atuação profissional atual. Esses saberes disciplinares são construídos pelos professores ainda na sua formação inicial. Segundo Tardif (2002), eles integram a prática pedagógica dos professores através das 
disciplinas oferecidas pela universidade, são saberes que correspondem aos diversos campos da nossa sociedade.

Os professores ainda relatam que buscam nas suas anotações das disciplinas cursadas na formação inicial subsídios para dar conta das suas aulas, isso é, trazem à sua prática saberes disciplinares da sua formação; pudemos constatar isso quando foi questionado sobre os elementos da formação inicial que foram significativos para dar conta da prática educativa na escola.

Então todas elas me ajudaram depois tinha as outras ali que ajudavam a lidar com alunos tinha disciplinas que não era as práticas mais que davam um bom auxilio sim, eu ainda busco algumas coisas que eu tenho anotadas, claro que vão se defasando, que o tempo vai passando, mais tem muita coisa que eu tenho lá em casa ainda que eu vou buscando da graduação, que eu vou buscando pesquisando e que eu consigo utilizar alguma coisa as vezes com algumas alterações, nos dias de hoje nas minhas aulas. (Professor Bob)

Todos eles a gente aproveita um pouco, as práticas coletivas e as individuais são conteúdos base da Ed. Física, e no resto todo, Educação Física e Saúde, as tendências pedagógicas é bom a gente ter a base, ver como trabalhar de acordo com o planejamento, as perspectivas que se encaixa. (Professora Sendy)

Esse ingresso do Bob no curso de Educação Física pelo incentivo da natação e do teor técnico exercido no treino se reflete muito na sua prática. Podemos identificar em nossas observações que Bob não deixa espaços para que seus alunos questionem ou criem em suas aulas, ele simplesmente transfere o conhecimento apreendido por ele na graduação para seus alunos. Freire (2011) observa que “[...] saber ensinar não é transferir conhecimento, mas criar as possibilidades para a sua própria produção ou a sua construção" (p.47), o professor deve sempre estar aberto aos questionamentos e angústias dos seus alunos frente aos conteúdos, possibilitando a eles dar sentido à sua vivencia em aula, caso contrário voltamos à educação bancária, cujos alunos são apenas vasilhas vazias a serem preenchidas por um conhecimento que é alienado a eles. Por isso, Freire (2011) insiste que "este saber necessário ao professor - de que ensinar não é transferir conhecimento" (p.47), o conhecimento deve fazer com que seu aluno possa refletir sobre a sua realidade, só se consegue isso com uma prática problematizadora, instigando no aluno o poder de compreensão do seu mundo. 
Durante a graduação os professores não participaram de grupos de pesquisa, Bob não participou de estágios não obrigatórios, já Sendy fez estágios não obrigatórios. Isso é comprovado na fala da professora abaixo.

Durante a graduação eu não fiz parte de grupos de pesquisa, mas eu fiz estagio não obrigatório, mas na área do bacharel, eu comecei no bacharel e depois passei para a licenciatura, e eu comecei com ginástica laboral, trabalhei dois anos no estagio não obrigatório de ginástica laboral. (Professora Sendy)

Esse tipo de formação que visa formar professores de Educação Física em licenciatura plena, o parecer CNE/CES no 776/97 buscou estabelecer orientações gerais para que os cursos estabelecessem diretrizes curriculares que dessem conta de cada área do conhecimento, formando um profissional apto para as duas áreas da Educação Física. Esse é o caso do professor Bob, que se formou nesse currículo que forma professores generalistas, que aprendem de tudo um pouco, que fazem da escola apenas uma atividade burocrática, pois não tem interesse na escola, tampouco na docência. Já Sendy é formada no parecer CNE/CP no 009/2001, que propõe toda uma nova organização para a formação docente, para que não se confunda licenciatura e bacharelado, isso implica em toda uma nova organização de currículos próprios para cada curso, mesmo assim Sendy começou seu curso no bacharel e após 3 semestres (1 ano e meio) passou para a licenciatura, isso implica na formação da professora que volta a aprender de tudo um pouco e indo à escola como uma formação defasada. Mesmo com isso os professores podem buscar na sua prática elementos para fazer dela um algo a mais, uma prática reflexiva junto aos seus alunos, mas isso depende do professor e da sua indagação pessoal sobre o mundo, a sua formação apenas o auxilia no seu percurso, mas é ele quem faz a sua prática pedagógica, podem fazer isso através de uma formação permanente, desde que ela o auxilie nesse processo.

Os professores buscam na formação permanente elementos para dar conta da sua prática pedagógica, podem ser de atualização daquilo que já conhecem da sua formação inicial ou algo novo, como veremos nas falas dos professores no decorrer desse texto.

A formação permanente é por Freire (2013) entendida como o movimento do ser mais, sendo contrário a concepção e práticas bancárias, que imobiliza e desconhece os homens como seres históricos e inacabados, por isso observa os seres humanos como inacabados e inconclusos, sendo os homens conscientes da sua inconclusão buscam o ser mais, 
Aí se encontra as raízes da educação mesma, como manifestação exclusivamente humana. Isto é, na inconclusão dos homens e na consciência que dela têm, Daí que seja a educação um quefazer permanente. Permanentemente, na razão da inconclusão dos homens e do devenir da realidade (FREIRE, 2013, p.102).

Os dois professores afirmam fazer formação permanente, Bob tenta nos esclarecer com suas palavras o que para ele é formação permanente, e também os cursos que ele faz anualmente e o motivo pelo qual faz esses cursos.

\begin{abstract}
Entendo formação permanente como um curso que você tem que fazer isso claro regularmente, isso o governo até no caso da escola, esta começando a oferecer um pouco mais, hoje eu estou fazendo um curso pro ensino médio, nos professores daqui estamos conseguindo tocar um curso ai bem legal, e os outros cursos ai pra nossa área da Educação Física, o interessante é a gente sempre buscar alguma coisa, porque tudo muda muito rápido[...] então eu procuro fazer curso quase que todo ano faço um curso de natação que é a minha área, e aqui na escola a gente tem esses cursos agora do ensino médio, e alguns pra mudar de letra o nosso nível. O governo meio que incentiva pela questão salarial para que a gente faça em um período tantas horas de curso, então você tem que fazer aqueles cursos para ter aquelas horas lá, se não você não consegue até ir crescendo nas letrinhas lá no nosso plano de carreira [...]. (Professor Bob)
\end{abstract}

Esse tipo de formação permanente se caracteriza como o que Freire (2013) chama de educação bancária, onde os cursos que são oferecidos são cursos desconectados da realidade dos professores, transformando os professores em vasilhas a serem preenchidas, cuja única ação deles é receber os depósitos, guardá-los e arquivá-los, no nosso caso as horas de cursos se tornam arquivos a serem acumulados para se transformar em bonificação salarial.

$\mathrm{Na}$ concepção "bancária" que estamos criticando, para a qual a educação é o ato de depositar, de transferir, de transmitir valores e conhecimentos, não se verifica nem pode verificar-se esta superação. Pelo contrário, refletindo a sociedade opressora, sendo dimensão da "cultura do silêncio" a "educação" "bancária" mantém e estimula a contradição. (FREIRE, 2013, p.82)

Sachs e Logan (1990 apud Day, 2001) dizem que esse tipo de formação permanente em vez de promover práticas reflexivas, capazes de entender, questionar e transformar a sua prática, encoraja o professor a se manter da forma que está e se aprofundar em práticas instrumentais, que podem ser alcançadas com receitas práticas que tem como objetivo o "experimentar e ver no que vai dar". 
Freire (2011) acrescenta ainda que ensinar não é transferir conhecimento e sim construir conhecimento, o professor deve estar envolvido nessa construção e junto fazer a construção envolvendo os alunos. A isso se estende a formação docente em que não haja apenas declamações de teorias sem a vivência delas, vejamos isso nas próprias palavras do autor.

Como professor num curso de formação docente não posso esgotar minha prática discursando sobre a Teoria da não extensão do conhecimento. Não posso apenas falar bonito sobre as razões ontológicas, epistemológicas e políticas da Teoria. O meu discurso sobre a Teoria deve ser o exemplo concreto, prático, da teoria. Sua encarnação. (FREIRE, 2011, p.47)

Já a professora Sendy fala da sua pós-graduação e dos cursos, mas vê a dificuldade de realizar esses cursos, tanto pela condição temporal dela, mas também pela raridade que esses cursos são oferecidos. Notamos na fala da professora Sendy o seu descontentamento com esse tipo de formação, que geralmente são formações que tem como objetivo instrumentalizar a prática do professor, não alcançando o objetivo de fazer o professor refletir.

Logo que eu me formei eu fiz a minha pós-graduação, ai eu tive um momento bem longo, foi durante um ano que eu estudei, fiquei estudando após eu me formar, mas depois disso eu faço alguns cursos que o estado oferece, município quando tem, e fora disso só estudo em casa mesmo, eu sair assim pra fazer curso é difícil, eu trabalho 60 horas, então é complicado. (Professora Sendy)

Observamos na fala da professora Sendy que a intensificação do trabalho atrapalha a formação permanente dos professores, pois não lhes sobra tempo para se dedicar a uma formação permanente de qualidade, e por muitas vezes, como nos diz Bob, faz o curso por incentivo salarial, deixando de lado seu papel principal, que é a pesquisa e a busca pelo novo saber. Essa formação, como nos diz Freire (2011): "Não há ensino sem pesquisa e pesquisa sem ensino. Esses fazeres se encontram um no corpo do outro." (p.30). Esse professor pesquisador ao conhecer o que ainda não conhece tende a anunciar a novidade aos seus alunos, dando sentido à sua pesquisa, à sua formação permanente, caso contrário voltamos a educação bancária que nada tem a acrescentar aos docentes, tampouco aos discentes. A formação permanente tem que ir ao encontro docente, dando sentido a ele, para que ele ao se apropriar dela possa dar sentido à sua prática pedagógica, 
aproximando o discente desse novo saber e que ambos possam refletir sobre ele dando sentido e aproximando da sua realidade.

Mesmo se a formação permanente dos nossos professores caminharem pelo viés do incentivo salarial, os professores da escola Dake fazem essa formação em busca de mais conhecimento ou então aprofundamento do conhecimento já adquirido como, podemos observar na fala dos professores quando perguntei a eles o motivo pelo qual eles fazem essa formação permanente.

Eu faço formação permanente primeiramente pela reciclagem, eu penso muito nessa reciclagem, eu vou ter que observar tudo e ter as mudanças devidas que como eu falei mudo muito rápido [...] [...] eu tenho que buscar essas informações, através de cursos pesquisas e as vezes não é só curso, é tu sentar um tempo na frente do computador entrar na internet e fazer um pesquisa tua ali, para ver como tu vai trabalhar e trazer coisas novas pra dentro da sala. (Professor Bob)

Pelo aprendizado saber novas maneiras de trabalhar com alunos, mas isso mesmo, ter novidades para passar para os alunos, mais conhecimento. (Professora Sendy)

Essa formação permanente que tem como intuito fazer com que o professor repense suas práticas e faça-o refletir sobre ela, Freire (2011) fala a importância dela para o professor. "Por isso é que, na formação permanente dos professores, o momento fundamental é o da reflexão crítica sobre a prática. É pensando criticamente a prática de hoje ou de ontem que se pode melhorar a próxima prática." (p.40).

Segundo Wittizorecki e Molina Neto (2005), as limitações das condições de trabalho e a intensificação das atividades docentes dificultam que o professor pense na sua carreira ou faça uma reflexão da sua prática.

Identificamos frequentemente avaliações, comentários e reflexões dos docentes a respeito de aspectos relacionados às dificuldades de não disporem de tempo para trocar experiências, avaliar suas práticas mais detidamente e articulá-las às ações de outros professores (pelo fato de possuírem muitas turmas, ministrando aula a estas, uma após a outra); pela sobrecarga de atividades, inclusive em mais de uma escola e por vezes em outros ramos de trabalho; além do cansaço físico e, sobretudo, emocional das jornadas diárias de ensino. (p.48)

Constatamos isso quando a professora Sendy fala de sua jornada de trabalho de 60 horas e das dificuldades que tem em fazer sua formação permanente, mas agora que se efetivou no estado e em 2015 se efetivará no município, entra na fase de estabilização do trabalho docente; segundo Huberman (1995), a fase de estabilização acontece entre 4 
a 6 anos de docência, onde o professor está mais seguro e confiante no seu trabalho, e também pela garantia do seu lugar de trabalho, que é o caso da professora Sendy, onde possibilitará a ela ter mais autonomia por estar agora fixada em uma instituição. Bob, em função da academia de natação, chega sempre em cima do horário em que vai para as turmas, e no diário de campo (17/09/2014) me relatou que no próximo ano (2015) vai fazer redução da sua carga horária na escola para se dedicar à academia de natação, ele está em fase de desinvestimento, onde segundo Hurbeman (1995), usa o exemplo que traduz o que acontece com o professor Bob, onde o professor tem interesses fora da instituição na qual leciona, e acaba tendo um desinvestimento sereno, que é o recuo do docente frente aos seus ideais e planos como professor.

\section{O contexto escolar e a interferência na prática pedagógica}

Vamos tratar agora dos fatores que interferem na prática pedagógica do professor e que nos mostra como os professores lidam com o dia-a-dia da escola e essas interferências. Segundo Tardif e Lessard (2009), desde que a docência moderna existe, ela é realizada em um lugar organizado, separado de outros lugares da vida cotidiana, esse lugar é a escola, a escola tem algumas características bem específicas, como não ser apenas um lugar físico, mas também um lugar social, e isso define como os professores vão se repartir para realizar as tarefas a eles incumbidos e também como vão planejar.

Sendo assim, professores afirmam que a escola é muito boa para se trabalhar, Bob complementa dizendo que a escola é boa de trabalhar pelo fato de ser uma escola de interior, e de que os alunos têm poucas vivências com atividades corporais nas aulas, e de que a grande maioria é filho de agricultores e ajudam seus pais e não tem muitas vivencias práticas, então há a possibilidade de trazer muitas novidades aos alunos. Freire (2011) diz que "ensinar exige apreensão da realidade" (p.67), ele complementa dizendo que não aprendemos para nos adaptar, mas para mudarmos a realidade que estamos inseridos, para intervir nela e assim recriá-la. Tardif e Lessard (2009) falam também que "um professor trabalha, portanto, com e sobre seres humanos. Ora, os seres humanos apresentam algumas características que condicionam o trabalho docente". Sendo a escola Dake uma escola de interior isso é um fator que interfere e condiciona o trabalho docente, pois ao mesmo tempo em que instiga os alunos a conhecimentos novos, traz a curiosidade dos colegas docentes que de alguma forma tentam acrescentar na aula do professor Bob, como vemos na fala dele a seguir. 
Mesmo sem tu comentar muito eles entram na conversa, "Há eu vi tua aula lá fora, a gostei disso aqui e tal, mas será que de repente o outro professor lá que eu vi ele faz a mesma tua aula e dá de uma forma um pouco diferente, utilizou outros materiais, isso é legal, sobre isso o pessoal conversa bastante, principalmente com as professoras de EDFI a gente troca muita ideia, muita ideia mesmo. (Professor Bob)

Segundo Tardif e Lessard (2009), essa colaboração entre os docentes acontece frequentemente, e sem nenhuma dúvida é extremamente boa, e é mantida pelos professores ao longo de diversas atividades escolares. Em nossa observação pude perceber que os professores se organizaram coletivamente para fazer um torneio interno de futsal, separaram as tarefas e os horários, indo além da sala de aula. Bossle (2008) observa que "coletivo é o que contempla muitas pessoas em torno de um ou mais objetos" (p.46), e em nossas observações somente esse movimento foi presenciado quando se trata de trabalho coletivo; Fusari (2006), citado por Bossle (2008), observa que isso não é comum em escolas públicas, e o autor cita pontos que dificultam esse tipo de trabalho, como por exemplo a ausência na formação inicial e continuada desta modalidade de prática, calendários escolares que não privilegiam encontros e também a ausência dos professores na confecção e na construção prática do Projeto Político-Pedagógico.

Segundo a professora Sendy, que está a pouco tempo na escola Dake, ela está observando e aberta a trabalhar em conjunto com outros professores.

Eu tento observar, eu to pouco tempo aqui então nos primeiro messes eu observo a rotina de cada um, como cada um trabalha, se alguém me aborda e me pergunta alguma coisa pra tentar trabalhar junto, eu estarei sempre aberta pra isso, mas por enquanto eu to só observando mesmo, o andamento da escola, até porque eu não conheço muito e to conhecendo ainda. (Professora Sendy)

Tardif e Lessard (2009) observam que esse tipo de relação exige "todo um jogo sutil de delimitações e negociação dos respectivos papéis nas interações concretas dentro de um estabelecimento" (p.183), e é isso que vimos Sendy fazendo em nossas observações, enquanto estava na escola observava toda a movimentação, e sempre estava disposta a ajudar os demais professores e também o corpo diretivo (Observação de campo dos dias 28 e 29 de agosto de 2014).

Os professores ainda relatam que não há interferência por parte da escola nem por parte do corpo diretivo quando se trata da atuação ou da construção do planejamento, mas Bob acrescenta que há colaboração entre os professores de Educação Física quando se trata de planejamento; vejamos a seguir. 
Não há essa influência, a gente mostra o nosso projeto em todo início de ano, dos planos de aula do plano de ensino, e a gente senta, nós professores de Educação Física no início do ano exclusivamente para trocar uma ideia e como a gente vai planejar e fazer esse planejamento anual, para cada ano a gente melhorar ele, fazemos algumas melhorias, algumas alterações e depois disso a gente vai sentando e cada um vai montando o seu até um pouco pela necessidade e por aquilo que tu viu nos outros anos, e nós montamos um, nós temos inclusive um que a secretaria tem ele, a gente montou um geral dos pequenos do primeiro ano até o ensino médio, se eu não me engano está ali na secretaria para ser observado por algum professor, o que tem ali é como se fosse um modelo, não necessariamente usamos aquele mas tem lá [...]. (Professor Bob)

Tardif e Lessard (2009) nos mostram que esse é o primeiro tipo de colaboração comum entre os professores entrevistados por eles, e que se repete em nossa entrevista principalmente com o professor Bob, essa colaboração para o planejamento do ensino entre os professores da mesma matéria, "contudo, essa colaboração para o planejamento do ensino não significa proceder de maneira idêntica em classe: é fixado em quadro comum, mas cada um mantém sua margem de manobra, sua zona de autonomia e de liberdade profissional.” (p.185)

Essa zona de autonomia e liberdade também pode ser notada nas falas de quando fala que não usa o modelo padrão, mas faz dele uma referência, usa aquilo que se encaixa melhor em suas aulas.

Procuro fazer pesquisas, o que é melhor trabalhar para aquela idade para aquela turma, então eu pesquiso muito isso e através isso eu vou montando meu planejamento e também nas experiências que eu tenho, então eu trabalho meu planejamento desta forma faço as pesquisas uso algumas leis e diretrizes que tem, procuro não fugir muito dela, mas tem algumas ali que as vezes eu vou pensando, não é muito isso que é interessante aquilo que eu estudei aquilo que eu aprendi que eu vou pesquisando, que eu vou avançando. (Professor Bob)

Já a professora Sendy, que entrou na metade do ano letivo, sentiu a falta do planejamento do antigo professor que estava na escola como ACT (admissão em caráter temporário), esse fator é um dificultador, segundo Tardif et al (2009), para que haja colaboração entre os professores é necessário que o grupo docente esteja estável, caso contrário fica difícil manter ou estabelecer uma relação entre os professores. O professor que antecedeu a professora Sendy não deixou um planejamento para que ela pudesse seguir, porque segundo Bob quando os professores de Educação Física montaram os seus planejamentos ele ainda não estava na instituição, quando ele chegou o ano letivo já havia 
começado. Vamos à fala da professora quando pergunto da interferência do corpo diretivo sobre o planejamento e se ela tem um planejamento.

Até agora não tive nenhuma interferência, inclusive quando eu cheguei aqui eu perguntei se o último professor tinha deixado o plano de ensino pro ano, ela me disse que não, que ele não tinha entregue nada, porque eu queria dar continuidade no plano dele, mas ela me disse que não, então eu busquei com os alunos, ver os temas que ele tinha trabalhado. (Professora Sendy)

Outro fator agora apontado pela professora Sendy é a infraestrutura da escola, segundo ela escolas como essa são difíceis de encontrar.

Eu cheguei aqui eu encontrei uma escola com ginásio, que é difícil de encontrar, até que a quantidade de materiais é razoável, tem apoio como sala multimídia, data show, sala de informática tem tudo isso. (Professora Sendy)

Tardif (2009) observa que a falta de recursos e a escassez de instrumentos pedagógicos são mencionados pelos professores como um fator de maior dificuldade da profissão, no nosso caso a Sendy elogia o espaço pedagógico da escola, ela foi ACT durante quatro anos, passou por muitas escolas, e segundo ela essa escola tem uma infraestrutura muito boa.

\section{Considerações Finais}

Para fazer a construção das considerações transitórias desse estudo de caso, buscamos nos amparar no objetivo principal desse artigo: identificar os saberes mobilizados pelo professor de Educação Física para dar conta da sua prática pedagógica. Constatamos em nosso estudo que os professores mobilizam saberes de sua formação inicial como base para dar conta da sua prática pedagógica, aperfeiçoando através de pesquisas, para sempre manter essas informações atualizadas, e também para dar conta das lacunas que a formação inicial generalista deixou nos professores.

A formação permanente que os professores fazem vêm ao encontro da realidade deles na escola, então eles fazem em busca de novos conhecimentos, mas nem sempre é o que eles encontram na realidade, se torna então somente mais uma parte burocrática a ser cumprida em prol de melhores salários. A escassez desses cursos e a intensificação do trabalho docente também dificultam os professores a buscarem esses cursos com mais efetividade.

Observamos também que existem fatores que interferem na prática dos professores, que podem ser positivos ou negativos. A boa estrutura é citada pelos 
professores como um ponto positivo e facilitador para a construção das práticas dos professores, o fato dos professores serem efetivos na escola também é citado como um facilitador, já que possibilita ao professor se apropriar da cultura escolar e dos outros professores, facilitando a construção da sua prática.

Como fatores negativos podem observar a intensificação do trabalho docente como um fator preponderante, a grande carga dos professores afeta diretamente no planejamento das aulas e da reflexão sobre elas, dificultando aos professores que elaborem melhor suas aulas, também a falta de formação permanente de qualidade e com uma maior intensidade foi observada como um fator negativo.

\section{Referências}

BOSSLE, F. O "eu do nós": o professor de educação física e a construção do trabalho coletivo na rede municipal de ensino de porto alegre. Porto Alegre. 2008

BRASIL. Conselho Nacional de Educação - Conselho Pleno, Resolução CNE/CP no 009/2001. Brasília.

Resolução no. 776/97. Brasília: Documenta, nº 319, mar/97.

DAY, C. Desenvolvimento profissional de professores: os desafios da aprendizagem permanente. Porto Editora, Porto-Portugal, 2001.

FIGUEIREDO, Z. C. C. Experiências Sociocorporais e Formação Docente em Educação Física. Revista Movimento, Porto Alegre, v. 14, n. 01, p. 85-110, janeiro/abril de 2008.

FREIRE, P. Pedagogia da autonomia: saberes necessários à pratica educativa. $43^{\mathrm{a}}$ Ed. São Paulo, Paz e Terra, 2011. p.143

FREIRE, P. Pedagogia do oprimido. 54a Ed. Rio de Janeiro, Paz e Terra. 2013. p. 253

HUBERMAN, M. O ciclo de vida profissional dos professores. In NÓVOA, A. (org). Vida de professores. 2 ed. Porto, Portugal: Porto Editora, 1995. p. 31-61.

LIBÂNEO, J. C. Didática. São Paulo: Cortez, 1994.

LUDKE. M.; ANDRÈ. M. E. D. A Pesquisa em educação: abordagens qualitativa. São Paulo: EPU. 1986

MACHADO, R. C. F. Autonomia. .In: STRECK, D. R. et al. Dicionário Paulo Freire. $2^{\text {a }}$ ed., Belo Horizonte: Autêntica Editora, 2009.p. 53-54

MOLINA, R. M.K. O enfoque teórico metodológico qualitativo e o estudo de caso: uma reflexão introdutória. In. MOLINA NETO. V.; TRIVIÑOS. A. N. A Pesquisa Qualitativa 
na Educação Física: alternativas metodológicas. Porto alegre: editora da UFRGS/SULINA, 1999. p. 95-105

NEGRINE, A. Instrumento de coleta de informações na pesquisa qualitativa. In. MOLINA NETO. V.; TRIVIÑOS. A. N. A Pesquisa Qualitativa na Educação Física: alternativas metodológicas. Porto alegre: editora da UFRGS/SULINA, 1999.p. 61-93

MOLINA NETO, V. Etnografia: uma opção metodológica para alguns problemas de investigação no âmbito da Educação Física. In. A Pesquisa Qualitativa na Educação Física: alternativas metodológicas. Porto alegre: editora da UFRGS/SULINA, 1999. p. 107-137

ROSSATO, R. Práxis. .In: STRECK, D. R.; REDIN, E.; ZITKOSKI, J. J. . Dicionário Paulo Freire. $2^{a}$ Ed.. Belo Horizonte: Autêntica Editora, 2009. p. 325-327

TARDIF, M. Saberes docentes e formação profissional. Petrópolis, Rio de Janeiro, 2002.

TARDIF, M.; LESSARD, C. O trabalho docente: elementos para uma teoria da docência como profissão de interações humanas. Petrópolis, Rio de Janeiro, Editora Vozes, 2009.

WITTIZORECKI, E. S.; MOLINA NETO. V. O trabalho docente dos professores de Educação Física na Rede Municipal de Ensino de Porto Alegre. Revista Movimento, Porto Alegre, v.11. n.1, p.47-70, janeiro/abril de 2005.

\section{Como citar este artigo:}

CONCEIÇÃO, Victor Julierme Santos da.; MANFIOLETI, Ramires Mendes. Os saberes mobilizados pelo professor de educação física para construção da prática pedagógica. Revista Ibero-Americana de Estudos em Educação, Araraquara, v.12, n.1, p. 19-36, 2017. Disponível em: 〈http://dx.doi.org/10.21723/riaee.v12.n1.7416>. E-ISSN: 19825587.

Data de submissão: dez/2014

Aprovação final: jan/2017 